\title{
O Psicólogo no Campo do Bem-Estar Social: atuação junto às famílias e indivíduos em situação de vulnerabilidade e risco social no Centro de Referência de Assistência Social (CRAS)
}

\section{The psychologist in the field of social social rights: acting with individuals and families in situation of vulnerability and social risk in CRAS}

\author{
Samila Marques Leão* \\ Universidade Federal do Rio Grande do Norte - UFRN, Natal, Brasil \\ I sabel Maria Farias Fernandes de Oliveira** \\ Universidade Federal do Rio Grande do Norte - UFRN, Natal, Brasil \\ Denis Barros de Carvalho*** \\ Universidade Federal do Piauí - UFPI, Teresina, Piauí, Brasil
}

\begin{abstract}
RESUMO
O presente estudo teve como objetivo estudar a atuação do psicólogo no Centro de Referência de Assistência Social (CRAS), a fim de identificar as práticas desenvolvidas por esses profissionais, caracterizando-as no tocante às ferramentas teórico-metodológicas utilizadas, e investigar se essas práticas estão de acordo com as determinações e diretrizes da Política Nacional de Assistência Social (PNAS). A estratégia de investigação utilizada para a coleta dos dados foi uma entrevista semiestruturada em profundidade, realizada com os psicólogos. Entre os principais resultados, verificou-se. Constatou-se um campo de trabalho complexo e permeado de contradições, que oscila entre a garantia de direitos e a manutenção de velhas práticas e dificuldades historicamente presentes na Política de Assistência Social, sendo o psicólogo diretamente afetado por essa ambiguidade e incerteza, somadas às lacunas da sua formação profissional no trato à questão social Questão Social e à demanda diversificada dessa política, exigindo deste profissional, principalmente, ações multiprofissionais e intersetoriais.
\end{abstract}

Palavras-chave: atuação do psicólogo, assistência social, política social.

\begin{abstract}
The present study aimed to studying the psychologist action in the Reference Center of Social Assistance (CRAS), to identify the practices developed by these professionals, characterizing such practices with regard to the theoretical methodological tools used and to investigate if these practices are in accordance with provisions and guidelines of National Policy of Social Assistance (PNAS). The investigation strategies used to collect data was a semi-structured interview in-depth conducted with the psychologists.
\end{abstract}


Among the main results it was verified a complex work field and full of contradictions, which oscillates between the guarantee of rights and the maintenance of old practices and difficulties historically present in the Social Assistance Policy, being the psychologist directly affected by this ambiguity and uncertainty, added to the gaps in their professional formation in dealing with social issues and to the diversified demand of this policy, requiring, mainly, multidisciplinary and intersectoral actions.

Keywords: psychologist acting, social assistance, social policy.

\section{I ntrodução}

Nas últimas décadas, a política de Assistência Social obteve conquistas legislativas e institucionais, focalizando suas ações na garantia de direitos socioassistenciais e de condições dignas de vida para os cidadãos brasileiros em situação de vulnerabilidade social que dela necessitam. Porém, a história da Assistência Social apresenta pelo menos quatro caminhos pelos quais suas práticas se realizam: 0 clientelismo, o primeiro-damismo ${ }^{1}$, a filantropia e o seu caráter de ajuda, caridade e benemerência (Oliveira, 2005).

As ações da Assistência Social, desenvolvidas tanto em âmbito público como privado, tinham um caráter emergencial, ou seja, era uma política de provimento de temporalidades, de ações pontuais e imediatas. Com isso, em seu percurso histórico percebem-se violações de direitos e práticas assistencialistas e paternalistas. Alternativas a esse modelo aparecem, principalmente, após a Constituição Federal de 1988, contexto que traz novas formas de conceber os determinantes macroestruturais da pobreza, abrindo caminho para, de fato, minimizá-la.

O nordeste brasileiro, espaço de elevada pobreza e desigualdade social, é uma região que necessita de estratégias que minimizem esta realidade e promovam inclusão social e garantias de direitos sociais, como as ofertadas nos Centros de Referência de Assistência Social (CRAS), instituições-chave da proteção social básica da Assistência Social e que têm como objetivo central a prevenção de situações de risco em contextos de pobreza, privação e fragilização de vínculos afetivos.

Essa realidade se deve, principalmente, à condição social e econômica da região. Das 16,27 milhões de pessoas que vivem em situação de extrema pobreza no Brasil, 52,5\% concentra-se na região Nordeste (Brasil, 2011). No estado do Piauí, há 21,3\% de habitantes na linha da extrema pobreza, o que equivale dizer que um em cada cinco habitantes encontra-se nessa condição (Teresina, 2011).

A cidade de Teresina, capital do Piauí, reflete esse quadro de extrema pobreza e desigualdade social. De acordo com Firme, Santos \& Baratta (2002), nos últimos 30 anos, a capital passou por uma "explosão urbana": em 1970 contava com 181 mil habitantes; em 
1996, havia cerca de 700 mil, passando a deter mais de $39 \%$ do contingente urbano do estado. Nesse processo, verifica-se o aumento pronunciado da população pobre, que, na capital piauiense, constitui cerca de $80 \%$ dos habitantes com renda per capita de até dois salários mínimos.

Dotar os municípios de locais que têm como função básica prevenir situações de risco potencial ao indivíduo e à sua família é a proposta da Política Nacional de Assistência Social - PNAS (2004), com a implantação dos CRAS nos municípios brasileiros. Estes espaços são unidades públicas, localizadas em contextos de vulnerabilidade social, que têm como objetivo o desenvolvimento de serviços que visam fortalecer os vínculos familiares e comunitários, bem como a ampliação do acesso aos direitos sociais (Brasil, 2009a, 2009b). Complementar à Proteção Social Básica, em que se situam os CRAS, a rede da Assistência Social contém o nível da Proteção Social Especial, com média e alta complexidade, que se refere a serviços especializados, de caráter mais complexo, tratando-se de um atendimento dirigido às situações de violação de direitos com ou sem rompimento de vínculos familiares e comunitários (Brasil, 2004).

Essa nova conformação (a partir de 2004) representa um momento histórico para o profissional da Psicologia, tendo em vista que a rápida expansão dos CRAS pelas cidades brasileiras amplia o mercado de trabalho para essa especialidade e alarga seu escopo de atuação dos tradicionais espaços para a política pública -, cuja participação direta nas ações da Assistência Social potencia mudanças em contextos de pobreza e violação de direitos.

$\mathrm{Na}$ condição de protagonista, junto com o assistente social, das mudanças nas condições de vida dos que necessitam da Assistência Social, o profissional de Psicologia deve pautar-se por parâmetros éticos e políticos na perspectiva de realizar uma prática de acordo com o proposto pela PNAS. Esta, operacionalizada no Sistema Único de Assistência Social - SUAS (2005), tem como um dos seus pressupostos a efetivação de uma Assistência Social na perspectiva do direito, realizada de forma integrada e articulada com as demais esferas da proteção social ${ }^{2}$. Essa diretriz requer atuação multiprofissional, em rede e intersetorial ${ }^{3}$, alocando o psicólogo em equipes compostas por assistentes sociais, pedagogos, advogados, entre outros profissionais.

A atuação nos CRAS exige dos profissionais o reconhecimento das demandas dos territórios de abrangência, considerando as várias dimensões que afetam o homem. Os profissionais precisam ocupar-se das situações que demandam cuidados e atenção, realizando intervenções que extrapolem o modelo individualizante ${ }^{4}$ (homem é causa e efeito do seu comportamento), buscando estratégias de trabalho que minimizem as desigualdades sociais e as violações de direitos. 
As atividades desenvolvidas nos CRAS devem ser principalmente (Brasil, 2006; 2009a; 2009b):

- Vigilância social, que visa à “(...) produção e sistematização de informações que possibilitem a construção de indicadores e de índices territorializados das situações de vulnerabilidades e riscos que incidem sobre famílias/pessoas (...)" (Brasil, 2006, p. 31);

- Mapeamento do território, por meio do levantamento das instituições e/ou serviços que existem na localidade;

- Busca ativa ou procura intencional de usuários que necessitam dos serviços do CRAS;

- Acolhida, ação que busca uma “(...) escuta empática - no lugar de uma atenção "burocrática" - e a expressão da subjetividade, entendendo essa família a partir da vivência singular e particular de seus membros (...)" (Brasil, 2006, p.28);

- Encaminhamento para outros espaços e serviços, no sentido de facilitar o acesso das famílias aos benefícios, programas e projetos da política social;

- Visita domiciliar para compreender a realidade do grupo familiar, suas necessidades e potencialidades, fortalecer os vínculos familiares e comunitários (Brasil, 2006);

- Acompanhamento familiar, atividade principal e base de todas as ações do CRAS, que deve acontecer desde a entrada, ou seja, da acolhida do usuário, passando por procedimentos como encaminhamento e inserção em grupos de convivência e serviço socioeducativo;

- Articulação da rede de serviços socioassistenciais, que viabiliza o acesso aos serviços socioassistenciais (por exemplo, Centro de Referencia Especializado da Assistência Social - CREAS), assim como, o acompanhamento e o monitoramento desses serviços;

- Articulação da rede de serviços intersetoriais, que viabiliza o acesso aos serviços setoriais (Saúde, Educação, Saneamento Básico, Habitação);

- Grupos com atividades socioeducativas, que englobam grupos de convivência e fortalecimento de vínculos.

As ações prescritas pelo Ministério do Desenvolvimento Social e Combate a Fome (MDS) colocam o psicólogo frente a diversos desafios e limites, principalmente no que se refere à adequação do seu trabalho ao contexto da Assistência Social. Esses desafios se justificam em parte pelo histórico da profissão, cujo o percurso de evolução histórica revela uma ciência e profissão em que seus pressupostos teórico-metodológicos estiveram durante muito tempo hegemonicamente voltados para outras finalidades - que não 0 combate às sequelas da Questão Social. Tais pressupostos mediavam a realização de diagnósticos e procedimentos de seleção e 
classificação, cujos instrumentais básicos foram os testes psicológicos. Também priorizou como público-alvo de suas intervenções outros segmentos sociais, com características distintas dos principais usuários da atual política social.

O quadro acima se justifica porque a história da profissão é estreitamente vinculada à ideia de neutralidade e objetividade. Esse contexto enseja a criação de inúmeros laboratórios experimentais e o desenvolvimento dos testes, que tem o objetivo de oferecer "métodos mais objetivos para o conhecimento do homem, para a medição dos comportamentos e seu ajuste à ordem social vigente" (Dimenstein, 2000, p. 101).

No Brasil, o conhecimento psicológico sofreu grande influência da Europa, principalmente da França, com o modelo da medicina mental, e dos Estados Unidos, com os testes mentais. Dos Estados Unidos tem-se a importação de instrumentos psicológicos para diferenciação entre indivíduos aptos e não aptos, seja para o trabalho ou para a escola, atribuindo tal diferença mental/intelectual principalmente à hereditariedade (Carvalho, 2007). Desta forma, muitos dos instrumentos de trabalho da Psicologia categorizavam e imprimiam diagnósticos classificatórios, emergindo práticas de enquadramentos, padronização de comportamentos e estereótipos de personalidades, deixando de fora um aspecto crucial para compreensão do psiquismo do homem, a instância social e histórica.

A regulamentação da profissão de psicólogo no Brasil (Lei n. 4.119, 1962), reconhece o lugar dos conhecimentos psicológicos aplicados, principalmente, a diagnósticos, orientações e seleções profissionais, orientações psicopedagógicas e soluções de problemas de ajustamento. Os dez primeiros anos após a regulamentação da profissão são marcados pela Psicologia Clínica como área de grande aplicabilidade, com predomínio do conhecimento psicanalítico e do psicoterapeuta como modelo de profissional (Carvalho, 2007).

Contudo, mais que a marcada preferência pela atividade clínica, o modelo de profissional liberal à luz da profissão médica se fez amplamente hegemônico (Yamamoto, 2003). Esta forma de atuação distanciava a Psicologia de reflexões sobre a realidade social, econômica e cultural do seu país, deixando a profissão distante do cotidiano, com práticas descontextualizadas, cuja base era permeada por uma psicologização dos problemas sociais (Guazina, 2009).

A hegemonia do modelo clínico levantou questionamentos por parte das entidades de representação profissional, que afirmavam um descompromisso da atuação psicológica com a realidade social. Merece destaque o papel do Sistema Conselhos e do Sindicato de Psicólogos de São Paulo que pontuam a necessidade de um compromisso social da profissão para com a maioria da população brasileira que não tem acesso aos seus serviços. Esses discursos surgiram, principalmente, em publicações e eventos da área, 
questionando a atuação e a formação do psicólogo, profissional historicamente voltado para as necessidades da elite brasileira (Ribeiro, 2010).

É nesse contexto de críticas e questionamentos sobre o perfil profissional do psicólogo, que emergem teóricos buscando revisar os referenciais existentes, criando novas formas de atuação para categoria profissional, novas estratégias de trabalho para novos espaços de trabalho profissionais conquistados, partindo de uma visão crítica e histórica da subjetividade.

Um desses movimentos é a Psicologia Social Comunitária, que emergiu ainda nos anos de 1960 no país, e que busca extrapolar o modelo clínico privado, extrapolando para contextos comunitários de baixa renda intervenções que objetivam a transformação da realidade social dos sujeitos, por meio do protagonismo dos atores sociais, da participação popular e da busca destes por melhores condições de vida.

Outro momento histórico importante para a inserção do psicólogo em outros espaços de atuação constituiu-se da participação do psicólogo na Luta Antimanicomial, na década de 1980, momento que define algumas das condições para a inserção da categoria, de forma extensiva, no campo do Bem-estar Social (Yamamoto, 2007). Portanto, nas últimas décadas, a profissão tem ocupado novos espaços de atuação, como a Saúde Pública, requerendo da categoria - recuo do modelo tradicional, substituído por práticas sociais comprometidas com a transformação da realidade social, sobretudo, baseadas na compreensão da subjetividade contextualizada com sua realidade cultural, socioeconômica, política etc.

Em que pesem as observações anteriores, uma questão se coloca para os que estão envolvidos direta ou indiretamente com a prática psicológica: trata-se da forma como o compromisso social vem sendo debatido até então, já que, segundo Yamamoto (2003), não se trata de com quem a Psicologia vem se comprometendo, mas na forma desse compromisso. Uma atuação pautada pelo compromisso social não significa apenas a inserção do profissional em contextos de pobreza, mas sim, realizar práticas críticas e transformadoras, que busquem romper com a naturalização dos fenômenos psicológicos e, partindo disso, pensar novas estratégias de trabalho.

Segundo Ximenes, Paula e Barros (2009) o deslocamento dos psicólogos dos espaços tradicionais para as vicissitudes existentes em espaços de convivência comunitária não deve ser apenas a extensão dos serviços psicológicos, mas sim, a adoção da ideia de comunidade como um local onde as pessoas se apropriam e constroem os significados, as singularidades e os afetos.

Ainda assim, vários estudos nacionais sobre a atuação do psicólogo no campo das políticas sociais demonstram a adaptação de modelos, muitas vezes de viés clínico tradicional ${ }^{5}$ ao campo das políticas 
sociais. Também são identificadas práticas individualistas e normatizantes, que compreendem a "natureza humana como essência universal, eterna e mutável" (Sanches \& Kahhale, 2003, p. $19)$, e práticas que visam ajustar o indivíduo às realidades vigentes. A título de exemplo dessas práticas, no campo da educação, têm-se a diferenciação de alunos aptos e não aptos, sendo que se atribui a causa do não aprendizado, quase que exclusivamente, ao aluno.

Na Saúde Pública, há preocupação do debate sobre formas de intervenção que ultrapassem os enquadres clássicos de uma clínica individual e privada - prática ainda predominante em nossos cursos de formação (Leite \& Duarte, 2005). Ao estudar as Unidades Básicas de Saúde de Teresina (PI), Dimenstein (1998) aponta as dificuldades e limitações do exercício profissional do psicólogo, como o grande número de faltas e atrasos e a evasão massiva dos pacientes, que abandonam prematuramente seu tratamento, como forma de mostrarem que "não compartilham do modus operandi das psicoterapias realizadas no espaço" (p. 76). No Rio Grande do Norte, verifica-se um número considerável de casos que reproduzem o modelo clínico tradicional de vertentes psicanalíticas, sem problematização acerca da adequação desse modelo teórico-técnico para as exigências do serviço público de saúde, ou de desenvolvimento de ações integradas em equipes multiprofissionais (Yamamoto, 2003).

Não se pode negar, contudo, que a profissão vem tentando avançar em busca de novas formas de trabalho, novos referenciais. Exemplo disso é a iniciativa do Conselho Federal de Psicologia para a criação de um Centro de Referências Técnicas em Psicologia e Políticas Públicas (CREPOP), espaço destinado a pesquisas sobre a prática dos psicólogos nesses espaços, que tem promovido debates e mostrado possíveis caminhos para a psicologia no campo social. O que se avalia aqui é que essa e outras tantas iniciativas no campo ainda não conseguiram romper com uma lógica histórica de atuação que ainda marca fortemente as práticas realizadas em espaços extremamente ampliados e diversos de trabalho.

Mais recentemente, as discussões sobre os limites e o foco do trabalho do psicólogo nas políticas sociais ganham força por ocasião do seu ingresso massivo na política de Assistência Social, sobretudo a partir de 2004 - com destaque para a proteção social básica, nos CRAS. Nesse âmbito, o trabalho volta-se para as famílias exclusivamente em situação de risco e vulnerabilidade e que necessitam obrigatoriamente de intervenção do Estado para sua sobrevivência. Suas demandas são de difícil manejo para o psicólogo, devido aos “(...) problemas materiais, concretos e que necessitam, em grande parte, de intervenções fora do escopo da clínica tradicional ..." serem a maior problemática dessa política (Oliveira, Dantas, Solon \& Amorim, 2011). Soma-se a isso, a dificuldade de 
trabalhar em um campo extremamente contraditório que, apesar de inúmeras conquistas no campo dos direitos sociais, está inserido em um contexto de agenda neoliberal, marcado por reduzido investimento no campo social, seja pelas privatizações dos serviços, seja pela focalização das ações nos grupos em situação de extrema pobreza.

Nesta direção, objetivou-se analisar as práticas psicológicas desenvolvidas em quatro CRAS da cidade de Teresina/PI, caracterizando tais práticas no tocante às ferramentas teóricometodológicas utilizadas e investigar se essas práticas estão de acordo com as determinações e diretrizes da PNAS para efetivação nos CRAS.

\section{Método}

\subsection{I nstrumento e procedimentos}

Esta pesquisa orienta-se pela perspectiva qualitativa que, de acordo com Rey (2003), tem seus princípios epistemológicos voltados para o conhecimento como produção construtivo-interpretativa e para o processo de produção de conhecimento com caráter interativo e inclusivo de aspectos que extrapolam a relação investigadorinvestigado.

A entrevista utilizada neste processo investigativo teve a forma semiestruturada e individual, utilizando-se a combinação de perguntas fechadas e abertas, com o objetivo de possibilitar ao sujeito a oportunidade de se colocar sobre a temática em questão. Para isso, elaborou-se um roteiro com dois blocos de questões: (1) dados pessoais e caracterização do local de trabalho e do município; e (2) atividades realizadas pelas psicólogas no CRAS. Cabe ressaltar que em alguns momentos as perguntas do roteiro não seguiram a ordem estabelecida, e a sequência dependeu da forma como a questão anterior fora respondida. Todas as entrevistas foram realizadas nos locais de trabalho das psicólogas - critério adotado por proporcionar ao pesquisador contato com a rotina diária de trabalho dos pesquisados.

Em etapa complementar à fala das entrevistadas, uma pesquisa a fontes documentais foi empreendida. Consultou-se relatórios mensais de atividades realizadas nos CRAS e o material produzido para capacitação profissional da Secretaria Municipal de Trabalho, Cidadania e Assistência Social (SEMTCAS) - documentos que se tornaram importantes fontes de informação para a contextualização da realidade local.

O material foi analisado pela técnica de análise de conteúdo (Bardin, 2011), que seguiu os seguintes passos: (1) transformação do conteúdo em unidades de análise, que são os elementos unitários a 
ser classificados - palavras e frases presentes nos textos ou nas falas; (2) codificação das unidades em categorias agrupadas considerando-se a parte comum existente entre essas (semelhança ou analogia); (3) descrição, realizada por meio da construção e organização das informações em tabela, apresentando tanto as categorias construídas, como a ocorrência por CRAS e psicólogo; (4) interpretação dos dados a partir do referencial teórico utilizado, materialismo histórico dialético ancorado em discussões marxianas.

Não se utilizou categorias pré-definidas, sendo estas construídas ao longo do processo de análise (Tabela 1 ). 0 emprego desta estratégia de análise possibilitou aos pesquisadores compreender o sentido das falas das profissionais, a realidade vivida por elas, fundamentando, assim, a reflexão a respeito da prática do psicólogo nos CRAS.

\subsection{Participantes}

A cidade de Teresina conta com 17 CRAS, sendo que estão divididos por quatro regiões (sul, sudeste, leste e norte). Optou-se por entrevistar um psicólogo do CRAS mais antigo de cada região (total de quatro entrevistas). Esta escolha se fundamentou em entrevistas exploratórias realizadas com funcionários da SEMTCAS, em Teresina, que apontaram a importância dos primeiros CRAS implantados e, entre esses, a presença de psicólogas que estão desde a implantação da unidade.

A população da pesquisa foi composta por oito profissionais de Psicologia, do sexo feminino, entre 29 e 32 anos de idade, e quatro delas solteiras. Seis das profissionais são formadas em instituições de ensino superior privadas, entre os anos de 2004 e 2007, com estágio curricular em subáreas como clínica, educacional, organizacional e hospitalar. Dessa população, sete possuem pós-graduações lato sensu (especializações em Psicologia), porém não especificamente na área da Assistência Social. A trajetória profissional delas realizou-se tanto pelo campo da Clínica (quatro) como pelo CRAS (três) e pela Psicologia do Trânsito (uma). Em relação ao tempo de trabalho no CRAS, há três psicólogas que atuam desde a sua implantação; as outras cinco estão entre seis meses a um ano e dois meses no CRAS. Todas possuem precarização do vínculo empregatício, com contratos de trabalho temporário realizados por empresas terceirizadas. Associado a isso, possuem uma carga horária semanal de 30 horas ininterruptas, com remuneração máxima de dois salários mínimos sem descontos.

\section{Resultados e discussão}


As atividades e ações que acontecem nos CRAS pesquisados estão, em sua maioria, em consonância com o que é previsto nos guias de "Orientações Técnicas: Centro de Referência da Assistência Social CRAS" (Brasil, 2006; 2009a) e no Manual "Papéis e atribuições dos diferentes membros da equipe de CRAS/Teresina da Secretaria Municipal de Trabalho, Cidadania e Assistência Social - SEMTCAS" (2010). Porém, observamos a quase inexistência de algumas atividades como a vigilância social e a territorialização. No total, há 18 ações e atividades realizadas nos CRAS. Dessas, 17 contam com a participação do psicólogo para sua execução (Tabela 1).

Tabela 01

Atividades/ações desenvolvidas em CRAS de Teresa-PI, por quantidade de CRAS e de psicólogos

\begin{tabular}{|c|c|c|}
\hline Atividades e açöes & $\begin{array}{l}\text { CRAS } \\
\mathrm{N}\end{array}$ & Psicólogos Envolvidos \\
\hline Vigilância Social & 02 & 0 \\
\hline Mapeamento do território & 02 & 01 \\
\hline $\begin{array}{l}\text { Articulação com a rede de } \\
\text { serviços socioassistencial }\end{array}$ & 04 & 04 \\
\hline $\begin{array}{l}\text { Articulaçäo com a rede de } \\
\text { serviços intersetorial }\end{array}$ & 04 & 04 \\
\hline Busca ativa & 03 & 08 \\
\hline $\begin{array}{l}\text { Planejamento das } \\
\text { atividades e açöes }\end{array}$ & 04 & 08 \\
\hline Registro das informações & 04 & 08 \\
\hline $\begin{array}{l}\text { Produçäo de material } \\
\text { informativo }\end{array}$ & 02 & 01 \\
\hline Acompanhamento familiar & 04 & 01 \\
\hline Acolhimento & 04 & 08 \\
\hline Encaminhamento & 04 & 04 \\
\hline Visita domiciliar & 04 & 07 \\
\hline Atividades coletivas & 04 & 02 \\
\hline Realização de gnupos & 04 & 08 \\
\hline Supervisora de estágio & 02 & 02 \\
\hline Capacitações profissionais & 01 & 02 \\
\hline Beneficios eventuais & 04 & 02 \\
\hline $\begin{array}{l}\text { Reunião com a gestão } \\
\text { municipal }\end{array}$ & 03 & 03 \\
\hline
\end{tabular}


A única ação dos CRAS pesquisados que não conta com a presença do profissional de Psicologia é a sistematização de informações sobre o território (vigilância social). Essa ação subsidia as estatísticas oficiais de indicadores socioeconômicos do território e são utilizadas para subsidiar recursos, estrutura física e informações básicas necessárias para nortear a quantidade de famílias/ano que os técnicos de referência devem atender. Do desconhecimento sobre o território podem derivar distorções sobre as reais necessidades das famílias, principalmente por estarem imbuídos de um “(...) projeto de vida já previamente definido - por eles próprios (ou da leitura que fazem dos documentos norteadores da política) - para a populaçãousuária dos serviços" (Macedo \& Dimenstein, 2009, p. 295). Quatro das oito entrevistadas revelaram desconhecer o porte do município, e sete psicólogas não tinham informações sobre o Índice de Desenvolvimento Humano-Município (IDH-M) e o número de famílias cadastradas no CRAS e beneficiárias do Programa Bolsa Família (PBF). Daí, não é possível realizar com fidedignidade a vigilância social, identificar o perfil de demandas da comunidade, elencar prioridades de trabalho, entre outras ações previstas. E mais, a distorção acima referida ocorre porque, por conta desse desconhecimento, os psicólogos acabam por priorizar o atendimento da demanda espontânea, de forma emergencial, sem continuidade, prestando apenas um suporte momentâneo. É o chamado plantão psicológico que, embora funcione como acolhimento, não avança (pela experiência encontrada), para uma ação de proteção social.

Problematiza-se a necessidade de os profissionais disporem de informações sobre as famílias do PBF e os beneficiários do Beneficio de Prestação Continuada (BPC) - usuários prioritários da Proteção Social Básica, bem como das incidências de descumprimento de condicionalidades (Brasil, 2006; 2009a). Essas informações evitam a realização de atividades sem planejamento. Além disso, afirmar que "o maior número [de usuários] que procura o CRAS é por causa do Bolsa Família", por si só, não diz sobre o público-alvo do CRAS; apenas sinaliza, de forma genérica, que são indivíduos em situação de pobreza e privação. Não qualifica suas necessidades, nem suas aspirações e seus desejos.

De acordo com Sawaia (1999), em seus estudos sobre exclusão, deve-se perguntar por sofrimento e felicidade para que se possa superar a concepção de que o pobre se preocupa, unicamente, com sua sobrevivência, não se justificando trabalhar com as emoções quando se trabalha com a fome. A autora acrescenta que adotar essa concepção é colocar no centro das atenções, na discussão da exclusão, a ideia de humanidade e do sujeito com suas diversas dimensões (família, lazer, trabalho e sociedade), e, nesse sentido, a exclusão pode significar tanto desejo, temporalidade e afetividade, como também, poder, economia e direitos sociais. 
O desconhecimento das psicólogas entrevistadas sobre o contexto das famílias não pode ser considerada isoladamente. A comunicação dos gestores (das secretarias de Assistência Social) aos técnicos que estão na ponta da rede, especialmente sobre os instrumentais de trabalho que os profissionais devem utilizar, assim como o acesso a esses materiais, é essencial para que se possa subsidiar o trabalho desses profissionais de uma forma mais complexa e global, considerando todo o contexto em que está inserido.

A atividade mapeamento do território é realizada de forma incipiente: apenas uma profissional de Psicologia realiza visita institucional. Essa atividade possibilita conhecer o local, a finalidade e o público de atendimento da instituição.

Uma psicóloga relata a realização de contrarreferência no CRAS em que atua: "Vem demanda de outras Secretarias, vem tipo um encaminhamento de outra Secretaria, para a gente acompanhar aquela família, vem do CREAS, da Secretaria de Saúde". A contrarreferência diz respeito às ações de encaminhamento que ocorrem após a referência (encaminhamento de um usuário para outros dispositivos da rede socioassistencial, como os CREAS e as instituições de abrigamento, ou intersetorial, como o Sistema de Garantia de Direitos, a Saúde Pública, a Educação, etc.). É o retorno do usuário a níveis menos complexos da rede referenciada. O fato de a psicóloga mencionar ações de contrarreferência revela indícios (não é possível afirmar mais que isso) de que há uma articulação na rede socioassistencial. Contudo, a ausência do mapeamento do território (apenas duas psicólogas se referem a essa prática), atividade essencial para identificar as instituições que podem realizar articulação e parcerias, pode obstaculizar a efetividade da Articulação Intersetorial e da Articulação com a Rede Socioassistencial. Isto porque esta articulação com as demais instituições do território pode ser meramente informal e assistemática.

As articulações Intersetorial e da Rede Socioassistencial são ações que buscam uma gestão territorial articulada, integrada e continuada. Quatro psicólogas entrevistadas afirmaram realizá-las em sua prática profissional. Apesar de todos os CRAS realizarem articulações com outros espaços, cinco psicólogas afirmaram ter dificuldades e obstáculos para concretizá-las, apesar de sua importância para a continuidade dos atendimentos aos usuários.

Um ponto a analisar é se, de fato, as práticas se caracterizam como articulações intersetorial e socioassistencial de acordo com o Guia de Orientação do CRAS (Brasil, 2006, 2009a). No discurso oficial, a articulação na rede socioassistencial ou intersetorial é possível quando instituições da rede planejam e executam trabalhos conjuntos. Considerada esse modelo, apenas duas psicólogas afirmam realizá-las, porém com grandes limitações. 
As dificuldades de articulação da rede encontradas pelas profissionais foram da seguinte ordem: 1) ações apenas setoriais, a exemplo da dificuldade de diálogo com a saúde (04 psicólogas): "eu acho que a saúde não dá, não dá, tipo assim, a saúde é a saúde" (P3); 2) escassez de locais e serviços para atender a demanda da população, por exemplo, para usuários de drogas psicotrópicas: "às vezes tem uma pessoa pedindo ajuda porque é usuário de drogas, quer ajuda, mas os locais que ele pode ser atendido pra fazer tratamento, a fila de espera é enorme" (P7); 3) fragilidade da rede: "ainda é frágil a questão da responsabilização, tipo da rede, a rede ainda é frágil" (P1); 4) ausência de monitoramento dos casos encaminhados para a rede: "o retorno, às vezes, o próprio usuário não dá retorno, mas a gente vai levando, isso não é nada que atrapalhe" (P2).

De acordo com o que está preconizado pela Constituição de 1988 e pelos documentos que regem a Assistência Social, sabe-se que, embora seja de competência desta política a proteção social dos indivíduos pobres, essa proteção não se faz sem articulação com outras políticas públicas, principalmente aquelas diretamente ligadas à promoção da emancipação dos indivíduos. Nestas estratégias, é imprescindível que a operacionalização das políticas seja feita de maneira que haja a articulação entre elas e entre suas ações, por meio de uma concepção democrática e horizontal. A complexidade dos problemas sociais envolve uma gama de ações integradas e contínuas, sendo que a falta dessa perspectiva gera atendimentos fragmentados e descontínuos que não considera o cidadão na sua totalidade e complexidade (Junqueira, 1997 e 2004, Leite \& Duarte, 2005, Bidarra, 2009).

No Brasil, as formas de pensar e fazer política são centralizadas e isoladas, sendo que cada área da política pública tem uma rede própria de instituições e/ou serviços sociais (Bourguignon, 1999). A Assistência Social é exemplo disso: possui um conjunto de entidades estatais e filantrópicas que prestam serviços na área de forma paralela às demais políticas e, muitas vezes, atendendo aos mesmos usuários.

Nesse sentido, o desafio atual é propor mudanças tanto no legislativo, como nos projetos governamentais mais amplos teriam de reformular suas estratégias de ação, sua destinação dos recursos públicos, sua estrutura organizacional e burocrática, no caminho de uma política mais eficaz, mais articulada e mais democrática (Leite \& Duarte, 2005).

Uma gestão que compreenda a necessidade da troca de olhares, de saberes e uma abordagem integral é de suma importância para a qualidade do serviço. O gestor da Assistência Social precisa ter a clareza da sua responsabilidade na efetivação da articulação, devendo este influir e colaborar para sua realização e continuidade (Brasil, 2009a). Também é de suma importância a participação dos técnicos 
de referência na articulação dos serviços, projetos, programas e espaços, sendo que nos CRAS pesquisados apenas metade das profissionais (quatro entrevistadas) estão envolvidas em articulações intersetoriais.

O trabalho em rede ou intersetorial é uma atividade bastante recente ao profissional de Psicologia (Oliveira et al., 2011). Existem dificuldades estruturais e operacionais para a concretude da intersetorialidade ou das ações em rede, limitando-se apenas à transferência de responsabilidade entre instituições, sem garantia de atendimento e acompanhamento do usuário por técnicos da política social. Associado a isso, a manutenção do modelo clínico individual de atendimento, tão recorrente nas práticas psicológicas em vários espaços das políticas públicas, desvia o esforço para o atendimento integral do usuário (Dimenstein, 2001; Ribeiro, 2010; Guimarães, 2011).

Em relação à busca ativa, as profissionais relatam-na como um momento em que fazem atividades (em geral, palestras e eventos) em outros espaços do território (escolas, postos de saúde, visitas domiciliares e institucionais, projeto Manhã de (idadania ${ }^{6}$ ), aproveitando para divulgar os serviços e ações do CRAS. Esse momento é visto pelas profissionais como um espaço interdisciplinar, pois são realizados com a presença do profissional de Serviço Social e/ou orientadores sociais do Projovem Adolescente, o que promove antecipadamente um diálogo entre os envolvidos na atividade, para que se possa realizar uma abordagem baseada na realidade da família ou do indivíduo.

O planejamento das atividades é uma constante no trabalho de todas as psicólogas, também tido como momento de interdisciplinaridade, em que os técnicos cooperam na construção do trabalho. Contudo, o que se verifica na prática são planejamentos realizados de forma isolada. Isso porque cada técnico do CRAS é responsável pelo planejamento e monitoramento de um projeto: os grupos dos idosos (duas psicólogas) e o Projovem (seis psicólogas). Dessa forma, os planejamentos acontecem para organizar atividades e ações com os orientadores sociais do Projovem e com os coordenadores do grupo de idosos, sem implicação de outros profissionais da equipe ou participação dos próprios usuários.

Macedo (2007), em sua pesquisa sobre atuação do psicólogo nas Unidades Básicas de Saúde e CRAS em Natal-RN, afirma que os psicólogos ainda abrigam-se em seus especialismos, com dificuldades de realizarem práticas multiprofissionais ou interdisciplinares ou terem novas experiências de trabalho em conjunto. $O$ planejamento deve ser um momento de organização do trabalho em equipe e espaço de construção de estratégias de trabalho de cada CRAS e da Secretaria Municipal de Assistência Social com todos os CRAS. A equipe que compõe o CRAS deve realizar um planejamento geral, 
levando em consideração o já existente no território e no CRAS, suas potencialidades, e, a partir disso, pensar as ações rotineiras de organização da unidade (Brasil, 2009a). Essa atividade é fundamental para a previsão orçamentária, para o cumprimento das funções de cada membro da equipe, para a avaliação dos caminhos escolhidos e percorridos, e se esses devem permanecer ou não.

Sobre os registros de informação, a análise dos resultados aponta a realização desta atividade em todos os CRAS, assim como a participação expressiva de todas as psicólogas na sua execução. Sobre essa ação, alguns pontos devem ser analisados. Primeiro, a necessidade do repasse de informações da gestão para os técnicos que estão no CRAS: duas psicólogas relataram não ter a ficha de atendimento sobre o histórico da família, instrumento-chave para o atendimento familiar. Outro ponto a se destacar é a excessiva preocupação dos profissionais com esta prática, corroborando os resultados encontrados por Oliveira et al. (2011), que discutem a burocratização presente no campo das políticas públicas, como também, a necessidade de cuidado do profissional em formar um quadro geral do que está sendo executado nos serviços, estratégia importante para um serviço de qualidade.

As psicólogas definiram o acompanhamento familiar como um momento de orientação e acolhimento, dentre outros desdobramentos, como a visita domiciliar e os encaminhamentos. Das profissionais entrevistadas, seis relataram realizar esta atividade. O acolhimento, realizado por todas as psicólogas, é por elas definido de várias formas: pode se consistir numa escuta qualificada ou psicossocial (cinco psicólogas), um momento para orientar/acolher as famílias, seja individualmente ou em grupo, e que visa à superação das suas vulnerabilidades sociais (cinco psicólogas), ou, ainda, pode ser simplesmente a realização de cadastro em programas sociais das famílias (duas psicólogas). Há casos em que o acolhimento também é tido como uma escuta psicológica para resoluções de problemas emocionais (três psicólogas), ficando o psicólogo encarregado de tratar assuntos de fundo emocional, embora essa ação possa ser realizada em conjunto com o assistente social. Os profissionais de Psicologia enfrentam duas dificuldades relacionadas à identidade historicamente construída sobre a profissão: ainda possuem um "olhar psicologizante frente à maioria das questões que chegam aos CRAS" e dificuldades para realizarem estratégias de promoção social e fragilização dos vínculos sociocomunitários, seja em trabalhos em grupo ou com instituições presentes no território (Macedo, 2007, p. 24).

Adicionalmente, as profissionais relataram que, após o acolhimento, podem acontecer desdobramentos como os encaminhamentos ou a inserção da família em grupos e/ou em programas sociais, porém nem todos os casos são monitorados de forma contínua, até que a 
família seja desligada. Em outros casos, o acolhimento encerra-se em si mesmo, considerando-se que as necessidades do usuário foram solucionadas com os recursos do acolhimento.

Então, em alguns casos, o desconhecimento da resolutividade da demanda, de suas necessidades e problemáticas, sem monitoramento dos desdobramentos do acolhimento, pode tornar esta ação um mero Plantão Social, reproduzindo antigos modelos da Assistência Social baseados no atendimento de emergência.

O encaminhamento também é realizado pelas psicólogas como sinônimo do acompanhamento familiar. Quatro das oito psicólogas relataram realizar o encaminhamento, que pode ser para instituições da Assistência Social (CREAS e Núcleo de Apoio Intergeracional ${ }^{7}$ ) ou de outras políticas, como o Centro de Apoio Psicossocial. Também aqui não se tem garantia da realização do monitoramento das ações efetivadas, e, consequentemente, não se sabe se o procedimento solucionou a demanda do usuário ou se outras ações foram tomadas para que houvesse efetividade na rede de assistência.

Além da acolhida e do encaminhamento, a visita domiciliar é tomada como partícipe do processo do acompanhamento familiar. É realizada pela maioria das psicólogas entrevistadas (sete), principalmente para investigar denúncias, orientar e realizar busca ativa de novos usuários do CRAS. Apesar de fazer parte do acompanhamento familiar, as psicólogas a realiza de forma pontual, sem continuidade, não monitorando o fluxo do usuário na rede de serviços.

Seis psicólogas afirmam realizar acompanhamento familiar, porém os relatos restringem-se a atividades de acolhida seguidas de encaminhamento (cinco profissionais). Apenas uma psicóloga descreveu sua prática de acordo com o que preconiza o Ministério do Desenvolvimento Social e Combate a Fome para essa atividade (Brasil, 2006, 2009a). Essa prática fundamenta-se num modelo fragmentado dos saberes, no qual o fluxo de atendimento limita-se à queixa do usuário que é atendido por um especialista. Se a demanda apresentada pelo usuário for de ordem social e/ou material, o especialista evocado é o assistente social; se for de cunho emocional, pede-se a presença do psicólogo.

Em relação às atividades coletivas, cinco psicólogas relataram a realização de um evento de grande importância para os usuários: "Manhã de Cidadania". Com esse evento, propõe-se, em um único espaço, garantir vários direitos sociais e civis necessários ao exercício da cidadania. Geralmente, ocorre num local do território de abrangência do CRAS, contando com serviços da Assistência Social, Saúde, Educação, Cultura e Lazer, fortalecendo ações intersetoriais e multiprofissionais, perspectiva esperada e determinada para o funcionamento do CRAS (Brasil, 2006; 2009a). As palestras também fazem parte da rotina das profissionais, acontecendo em diversas situações: participação em eventos na rede de serviços, participação 
nos grupos que existentes do CRAS, dentre outras. Em relação aos cursos, apenas uma psicóloga participa diretamente da organização e realização destes.

As atividades em grupo envolvem a participação de todas as psicólogas. Nessas ocasiões, são observadas atividades com os idosos (duas psicólogas) e os coletivos do Projovem Adolescente (seis psicólogas), sendo que, em ambos, são realizados trabalhos como oficinas educativas, de convivência e de reflexão, campeonatos esportivos, dinâmicas de grupo e aulas-passeio. As profissionais relataram que essa modalidade é familiar às suas atividades, pois tiveram disciplinas sobre manejo de grupo no curso de graduação em Psicologia. A realização dessas ações ocorre a partir das necessidades e desejos dos grupos e dos responsáveis por estes (orientadores sociais do Projovem e coordenadores do grupo de idosos), o que torna esse um modelo interessante, por não ser planejado antecipada e isoladamente. Essa forma de trabalho possibilita aos profissionais uma atuação interdisciplinar, pois envolve a troca de saberes, a escuta sobre o ponto de vista do outro profissional e dos usuários em relação a determinado fenômeno.

A supervisão de estágio é uma atividade relatada por duas psicólogas entrevistadas. Essa ação indica a ampliação dos espaços de atuação na formação de psicólogos, designando as políticas públicas como um campo de trabalho deste profissional, bem como potencializa a interlocução entre o exercício profissional e a academia.

A capacitação profissional, espaço de qualificação do trabalho no CRAS foi realizada somente uma vez, logo após a entrada das profissionais no serviço (relatado por duas psicólogas). Essa realidade não condiz com o previsto pela Norma Operacional Básica de Recursos Humanos do Sistema Único de Assistência Social (Brasil, 2006), que aponta a necessidade de espaços de capacitação, qualificação e formação continuada dos técnicos, para que os profissionais possam ter uma compreensão sobre os problemas mais complexos enfrentados cotidianamente.

As psicólogas também realizam atividades de concessão de benefícios eventuais, que são assistência em espécie ou material e serviços de reabilitação na comunidade, como doação de cestas básicas e do transporte eficiente ${ }^{8}$ para pessoas com deficiência. Essas atividades não se encontram previstas pela SEMTCAS sobre os papéis e as atribuições dos psicólogos, embora os CRAS ou instituições referenciadas do território de sua abrangência possam realizá-las (Brasil, 2006).

Por fim, a reunião com a gestão municipal conta com a participação de três psicólogas entrevistadas, sendo que duas delas relataram que essa atividade aconteceu apenas quando iniciaram seu trabalho no CRAS, quando também ocorreu uma capacitação da gestão municipal sobre os serviços do CRAS do município. Considera-se necessária 
uma gestão democrática, que deve prioritariamente abrir espaços de troca e debates, possibilitando a construção de novas estratégias de trabalho a partir da realidade vivenciada pelos profissionais que se encontram na ponta dos serviços, pois são eles que estão em contato direto com a realidade dos usuários e da comunidade que prestam atendimento.

\section{Dificuldades e desafios na atuação do profissional de Psicologia no CRAS}

As profissionais entrevistadas relataram dificuldades e obstáculos para a realização do trabalho de acordo com o preconizado pelo MDS, como a falta de recursos humanos e materiais, somada ao próprio modo de funcionamento das políticas, especialmente a setorialização; além da formação inadequada em relação às estratégias de enfrentamento às expressões da questão social, configurando sérios obstáculos para atuação do psicólogo.

Sobre o primeiro ponto, a falta de recursos humanos e materiais, as profissionais relataram a necessidade de um maior número de profissionais e de outras especialidades (como advogado e educador físico), principalmente, no sentido de complementar suas práticas devido à diversidade de demanda do CRAS. A ausência e morosidade na aquisição de recursos materiais é o obstáculo mais recorrente (06 psicólogas), justificado, principalmente, pela burocracia presente no serviço público. A realidade do pouco repasse de recursos financeiros para política da Assistência Social está presente em toda a trajetória brasileira, que sempre desenvolveu suas atividades com parcos recursos financeiros, o que a deixou incapacitada para ofertar mínimos sociais ${ }^{9}$ de proteção àqueles que dela precisavam. Essa realidade traz implicações tanto para a gestão do trabalho, como também afeta a qualidade dos serviços socioassistenciais e a mediação dos direitos (Araújo, Pereira, Guilhon \& Sousa, 2008).

Outra dificuldade relatada pelas psicólogas é a falta de articulação entre os setores da política social. É a própria estruturação da política pública, setorizada, que rompe a lógica de totalidade e complexidade da realidade social, sendo incapaz de enfrentá-la eficazmente. Nesse modelo de elaboração da política pública, resta aos profissionais o esforço para executar as ações de modo a mediar as relações sociais intersetorialmente, ainda sob o risco de reproduzir a lógica individualizante e fragmentada.

A formação insuficiente para o trabalho na política pública marca o discurso das psicólogas (seis) sobre as dificuldades e os obstáculos para o trabalho nos CRAS de Teresina: "Eu acho que não vi quase nada [sobre política pública] na faculdade"; "Na graduação, poderia ter visto mais sobre a Psicologia Social, ter mais ênfase, ter estágio; 
não fazem na área, aí, é limitado"; "A gente acaba mesmo que, na prática, tendo que realmente aprender". De acordo com Bastos et al. (2010), esse cenário é nacional. Os atuais psicólogos brasileiros reconhecem a distância existente entre suas aprendizagens na graduação e as demandas do exercício profissional, verificando-se uma defasagem entre o que é necessário para bem exercer a profissão e o que Ihes é ensinado nos cursos. Em âmbito local, Carvalho (2007) pontua que a formação do psicólogo em Teresina é inadequada para o contexto das políticas sociais, principalmente pela formação, o viés clínico e a ausência de uma fundamentação teórica adequada ao contexto.

As questões mais problemáticas no ensino superior encontram-se na formação científica do aluno, assim como, nas “(...) competências para trabalhar com unidades de análise mais complexas que não o indivíduo, tais como grupos e organizações..." (Bastos, Gondim, Borges-Andrade, 2010, p. 26), sendo que, as competências como a avaliação psicológica e a clínica, áreas clássicas da profissão, são reconhecidas como mais desenvolvidas nos cursos, revelando, assim, o viés clínico presente em grande parte do sistema de ensino da Psicologia. Existe uma desarticulação entre a formação e a prática, entre o fazer e o saber, que pode gerar o praticismo, que se resume à ausência de reflexões sobre a prática, estando o profissional imerso em um tarefismo no seu cotidiano e atravessado por demandas administrativas e emergências. Assim, esse profissional não avalia e critica suas próprias ações, e consequentemente, não consegue alcançar a mudança e a aquisição de novos saberes, recuando seu papel político ${ }^{10}$ (Senra, 2009).

Outro obstáculo presente no discurso das psicólogas (cinco) refere-se à identidade profissional. Há dificuldade em perceber diferenças entre sua atuação e a do assistente social, e quando essas existem estão na forma de execução das atividades e ações. "Para te falar a verdade, eu não vejo muita diferença [entre a atuação do psicólogo e a do assistente social], não. A única diferença é que eu acho que a gente tem mais privilégio que eles nas questões de atendimento, que a gente pode atender ele [o usuário] e saber e ver mais a questão do CID". Nessa lógica, as psicólogas responsabilizam-se ou são mais responsabilizadas por assuntos ligados à integridade emocional e à saúde mental; aos assistentes sociais cabem assuntos relacionados à garantia de direitos (moradia, benefícios, cestas básicas) e à escrita do parecer social - atividade exclusiva deste profissional. Disso infere-se certa necessidade de definição de papéis entre as categorias profissionais, mas que resvala num "especialismo". Cada "área" fica com a responsabilidade de uma dimensão do homem, seja emocional, seja material.

Os psicólogos que trabalham na Atenção Básica da Saúde Pública e na Proteção Social Básica da Assistência Social possuem modos de 
trabalhos ainda pautados por uma lógica presa às barreiras das especialidades, acabando por psicologizar ou reduzir o individuo a três dimensões: "1) aos processos macrossociais ou macro ou micro políticos que atravessa a questão saúde-adoecimento; 2) ao malestar e sofrimento de indivíduos e famílias que procuram esses serviços; e até mesmo 3) ao mal-estar deles próprios, profissionais que atuam nesse campo (Macedo, 2007, p. 146).

As experiências exitosas da Psicologia no que invertem essa lógica de psicologização podem ser exemplificadas pelos avanços no campo da Saúde Mental, que tem desconstruído a ideia da loucura como patologia estritamente médica e biológica, por meio de práticas e saberes que resgatem a cidadania (Rosa, 2003). Também se pode considerar a problematização sobre o escopo da clínica ampliada, flexibilização a ideia de setting terapêutico para dispositivos de escuta e intervenção, como encontros, passeios, visitas domiciliares (Soares, Susin \& Warpechowski, 2009).

\section{Considerações finais}

Os CRAS, espaço de demanda que envolve diretamente o modo como a sociedade capitalista se estrutura e as reais consequências dessa lógica, como situações de pobreza, desigualdade social e precarização das políticas públicas, leva ao questionamento do lugar que o psicólogo ocupa nesse campo.

Apesar dos inúmeros avanços do SUAS e da sua rápida expansão no contexto brasileiro, tem-se, concomitante a isso, vivenciado o aprofundamento da precarização no campo das políticas públicas e nas relações de trabalho dos profissionais envolvidos nesses espaços. São profissionais que, na rotina dos serviços, muitas vezes burocráticos e hierárquicos, terminam por subordinar-se ao processo de alienação e a terem restringida sua autonomia técnica.

O psicólogo necessita analisar sua atuação de diversos ângulos, pois se encontra inserido em uma política que está edificando sua estrutura e organização, mas que, apesar dos avanços legislativos e operacionais, ainda descaracteriza seus ideários. Também precisa estar atento aos rumos e percursos da sua profissão, no sentido de buscar referências, claras e operacionais, que estabeleçam quais suas atribuições e competências nesse espaço.

Neste estudo, constatou-se que os profissionais encontram-se em um espaço que muito condiz com o preconizado pelo MDS, principalmente, em relação à estrutura física e organizacional, desenvolvendo ações e atividades que são previstas pelos órgãos competentes pela política. Porém, as estratégias de trabalho merecem uma análise cuidadosa, pois, muitas vezes, são impostas aos profissionais. Além disso, as relações de trabalho estabelecidas 
nos CRAS inviabilizam atividades continuadas e formação de equipes qualificadas. Os profissionais vivem constantemente a instabilidade do trabalho, sem diretos trabalhistas previstos para qualquer trabalhador e pela própria política do SUAS. Essa realidade muito obscurece os avanços da política e revela a necessidade de se empreender esforços para que a Assistência Social se consolide, de fato, como política pública.

Apesar das limitações apontadas, pode-se observar no trabalho do psicólogo avanços condizentes ao ideário da garantia de direitos e cidadania: 1) a preocupação de registrar as informações em instrumentais que facilitem o exercício profissional de uma forma mais qualificada e organizada, ajudando na produção de dados para a gestão; 2) a presença de um profissional responsável pelo PBF no espaço do CRAS, que, apesar de não estar sendo realizado de forma integrada à equipe da unidade, essa proximidade física possibilita a oferta simultânea e sistemática de renda e serviços socioassistenciais, potencializando a capacidade preventiva do CRAS; 3) o esforço de realizar a articulação entre os profissionais envolvidos na demanda do usuário (reuniões, encontros etc.), desenvolvendo, assim, estratégias criativas de trabalho que potencializam ações e recursos já existentes; d) a persistência dos profissionais que não se abatem com as dificuldades e os obstáculos encontrados no cotidiano e nos limites da Política de Assistência Social; e) e a compreensão da Psicologia como área importante no espaço das políticas públicas, e, em específico, da Assistência Social.

Nesta direção, a Psicologia pode fundamentar suas práticas em perspectivas inovadoras de trabalho e, sobretudo, extrapolar o viés individualista e normatizador que, por décadas, hegemonicamente, embasaram o trato às expressões da questão social. Espera-se que esta pesquisa auxilie na construção de uma profissão comprometida com o enfrentamento da questão social e na consolidação da Política de Assistência Social baseada na garantia dos direitos sociais à população.

\section{Referências}

Araújo, C. C.; Pereira, M. E. F. D.; Guilhon, M. V. M.\& Sousa, S. M. P. S. (2008) A gestão do trabalho no âmbito do SUAS: uma análise com base em resultados de pesquisa avaliativa. In Anais do ABEPSS Associação Brasileira de Ensino e Pesquisa em Serviço Social, São Luís, Maranhão, (CD-ROM). Recuperado em 05 fevereiro, 2012 de <http://www.gaepp.ufma.br/site/producao_cientifica_userview/downl oad. php?id=170>

Bardin, L. (2011). Análise do conteúdo. São Paulo: Edicoes 70. 
Bastos, A. V. B.; Gondim, S. M. G.\& Borges-Andrade, J. E. (2010) O psicólogo brasileiro: sua atuação e formação profissional. $O$ que mudou nas últimas décadas? In O. H. Yamamoto \& A. L. F. C. Costa (Orgs). Escritos sobre a profissão de psicólogo no Brasil (pp. 263278). Natal, RN: EDUFRN.

Bidarra, Z. S. (2009) Pactuar a intersetorialidade e tramar as redes para consolidar o sistema de garantia de direitos. Revista Serviço Social \& Sociedade, 99, pp. 487- 497.

Bourguignon, J. A. (1999) Concepção da rede intersetorial. In: NUPES - Núcleo de Pesquisa: desigualdade e exclusão no espaço local, Recuperado em 29 março, 2010, de <http://www. uepg.br/nupes/intersetor.htm>

Brasil (1988) Constituição da República Federativa do Brasil, Brasília, DF. Recuperado em 20 janeiro, 2012, de <http://www. planalto.gov.br/ccivil_03/Constituicao/Constitui\% C3\% A 7ao.htm>

Brasil, Ministério do Desenvolvimento Social e Combate a Fome. Secretaria Nacional de Assistência Social (2004) Política Nacional de Assistência Social. Brasília: DF. Recuperado em 20 de janeiro de 2012 de: <http://www. sedest.df.gov.br/sites/300/382/00000877. pdf> Brasil, Ministério do Desenvolvimento Social e Combate a Fome. Secretaria Nacional de Assistência Social. (2006) Guia de Orientação Técnica - $\mathrm{n}^{\circ} 1$. Proteção Social Básica de Assistência Social. Brasília, DF. Recuperado em 20 de janeiro de 2012 de: <http://www.cmas.piracicaba.sp.gov.br/docs/guia_orientacao_tecnic a.PDF>

Brasil, Ministério do Desenvolvimento Social e Combate à Fome. Secretaria Nacional de Assistência Social. (2009a) Orientações Técnicas: Centro de Referência de Assistência Social. Brasília, DF. Recuperado em 20 janeiro, 2012, de <http://www.mds.gov.br>

Brasil. Ministério do Desenvolvimento Social e Combate a Fome. Secretaria Nacional de Assistência Social. (2004) Política Nacional de Assistência Social. Brasília, DF. Recuperado em 20 janeiro, 2012, de <http://www.sedest.df.gov.br/sites/300/382/00000877.pdf>

Brasil. Ministério do Desenvolvimento Social e Combate à Fome. Secretaria Nacional de Assistência Social. (2009b) CRAS: A melhoria da estrutura física para o aprimoramento dos serviços: orientação para gestores e para projetistas municipais. Brasília, DF. Recuperado em 20 janeiro, 2012 de <http://www.mds.gov.br>

Brasil, Ministério do Desenvolvimento Social e Combate à Fome. Secretaria Nacional de Assistência Social (2011) O perfil da extrema Pobreza com base nos dados preliminares do universo do Censo 2010. Brasília, DF. Recuperado em 20 janeiro, 2012 de <http://www.mds.gov.br>

Carvalho, D. B. (2007) O trabalho do docente em psicologia e o enfrentamento da violência contra criança e adolescente: uma 
experiência Teresinense. Tese de Doutorado em Psicologia. Universidade Federal do Rio Grande do Norte, Natal, RN, Brasil.

Dimenstein, M. (1998) O psicólogo nas unidades básicas: desafios para formação e atuação profissionais. Revista Estudos de Psicologia, 3, (1), pp. 53-81.

Dimenstein, M. (2001) O psicólogo e o compromisso social no contexto da saúde coletiva. Revista Psicologia em Estudo, Maringá, v. 6 (2), pp. 57-63.

Firme, D. P.; Santos, A.; Baratta, T. C.; (Org.) (2002) Estudo de Caso: Projeto Vila-bairro: Teresina-Piauí. Rio de Janeiro: IBAM.

Guazina, F. M. N. (2009) A psicologia nos espaços públicos de saúde: discussões sobre integralidade e cuidado. Dissertação de Mestrado em Psicologia, Pontifícia Universidade Católica do Rio Grande do Sul. Porto Alegre, RS, Brasil.

Guimarães, S. B. (2011) A Atuação do psicólogo no contexto das referências ambulatoriais em saúde mental de Aracaju - SE. Dissertação de Mestrado em Psicologia, Universidade Federal do Rio Grande do Norte. Natal, RN, Brasil.

Junqueira, L. A. P. (1997) Novas formas de gestão na saúde: descentralização e intersetorialidade. Revista Saúde e Sociedade, 6 (2), pp. 31-46.

Junqueira, L. A. P. (2004) A gestão intersetorial das políticas sociais e o terceiro setor. Revista Saúde e Sociedade, 13(1), pp. 25-36.

Libâneo, J. C. (2004) Psicologia educacional: uma avaliação critica. In S.T.M. Lane, W. Codo (Orgs.) Psicologia social: o homem em movimento (pp. 154-180). São Paulo, SP: Brasiliense.

Lei no 4.119, 27 de agosto de 1962. (1962) Dispõe sobre os cursos de formação em Psicologia e regulamenta a profissão de Psicólogo. Brasília, DF. Recuperado em 20 janeiro, 2012, de <http:// www. pol.org. br/pol/cms/pol/legislacao/normatizacao/ > Leite, M. R. S. D. T., Duarte, V. C. (2005) Desafio da articulação entre políticas setoriais e intersetoriais: o caso da educação. In: Anais de $X$ Congreso Internacional del CLAD sobre la Reforma del Estado y de la Administración Pública (pp. 18-21). Santiago, Chile.

Lo Bianco, A. C.; Bastos, A. V. B., Nunes, M. L. T., \& Silva, R. C. (1994) Concepções emergentes na psicologia clínica: implicações para a formação. In: Psicólogo brasileiro: práticas emergentes e desafios para a formação (pp. 7-76). São Paulo: Casa do Psicólogo.

Macedo, J. P. S. (2007) O psicólogo no campo do Bem-Estar: cartografias de práticas na saúde e assistência social. Dissertação de Mestrado em Psicologia, Universidade Federal do Rio Grande do Norte. Natal, RN, Brasil.

Macedo, J. P., Dimenstein, M. (2009) Psicologia e a produção do cuidado no campo do bem-estar social. Revista Psicologia e Sociedade, 21(2), pp. 293-300. 
Oliveira, I. F.; Dantas, C. M. B.; Solon, A. F. A. C.; Amorim, K. M. O. (2011) A prática psicológica na proteção social básica do SUAS. Psicologia e sociedade, 23, n. SP.

Oliveira, I. M. (2005) Assistência Social pós-LOAS em Natal: a trajetória de uma política social entre o direito e a cultura do atraso. Tese de Doutorado em Serviço Social, Pontifica Universidade Católica de São Paulo. São Paulo, SP, Brasil.

Rey, F. L. G. (2003) Pesquisa qualitativa em psicologia: caminhos e desafios. São Paulo: Thompson.

Ribeiro, A. B. O psicólogo na proteção social especial: atuação junto às vítimas de violação de direitos no CREAS. Dissertação de Mestrado em Psicologia, Universidade Federal do Rio Grande do Norte. Natal, RN, Brasil.

Rosa, E. Z. (2003) Psicologia na saúde mental: em busca de uma leitura crítica e de uma atuação compromissada. In: A. M. B. Bock (Org.) A perspectiva sócio-histórica na formação em psicologia (pp. 192-210). Petrópolis, RJ : Vozes.

Sawaia, B. B. (1999) O sofrimento ético-político como categoria de análise da dialética da exclusão/inclusão. In: B.B. Sawaia (Org.). As armadilhas da exclusão: análise psicossocial e ética da desigualdade social (pp. 97-118). Petrópolis, RJ : Vozes.

Sanchez, S. G; Kahhale, E. M. (2003). História da psicóloga: a existência de uma leitura crítica. In A, M. B, Bock (Org.) A perspectiva sócio-histórica na formação em psicologia (pp.11-40). Petrópolis, RJ : Vozes.

Senra, C. M. G. (2009) Psicólogos sociais em instituição pública de assistência social: analisando estratégias de enfrentamento. Tese de Doutorado em Psicologia, Pontifica Universidade Católica de Campinas. Campinas, SP: Brasil.

Soares, J. N., Susin, L.\& Warpechowski, M. B. (2009) A clínica ampliada na assistência social. In: L. Rodrigues \& N. Guareschi, Políticas públicas e assistência social: diálogos com as práticas psicológicas (pp. 151-160). Petrópolis, RJ: Vozes.

Teresina (2010) Papéis e atribuições dos diferentes membros da equipe de CRAS/Teresina. Teresina: SEMTCAS.

Ximenes. V. M, Paula. L. R. C \& Barros. J. P. P. (2005) Psicologia comunitária e política de Assistência Social: diálogos sobre atuações em comunidade. Revista Psicologia Ciência e Profissão, 9(4), pp. 686699.

Yamamoto. O. H. (2003) Questões sociais e políticas públicas: revendo o compromisso da Psicologia. In: A.M.B.Bock, Psicologia e o compromisso social. São Paulo: Cortez.

Yamamoto. O. H. (2007) Políticas sociais, "terceiro setor" e "compromisso social": perspectivas e limites do trabalho do psicólogo. Revista Psicologia \& Sociedade, 19(1), pp. 30-37. 
Isabel Maria Farias Fernandes de Oliveira, Denis Barros de Carvalho

O Psicólogo no Campo do Bem-Estar Social: atuação junto às famílias e indivíduos em situação de vulnerabilidade e risco social no CRAS

\section{Endereço para correspondência \\ Samila Marques Leão}

Faculdade Santo Agostinho, 665, São Pedro, CEP 64019-625, Teresina - PI, Brasil.

Endereço eletrônico: samilaleao@gmail.com

I sabel Maria Farias Fernandes de Oliveira

Universidade Federal do Rio Grande do Norte, Centro de Ciências Humanas, Letra e Arte. Campus Universitário - Departamento de Psicologia, Lagoa Nova, CEP 59078970, Natal - RN, Brasil.

Endereço eletrônico: fernandes.isa@gmail.com

\section{Denis Barros de Carvalho}

Universidade Federal do Piauí, Centro de Ciências da Educação, Campus Universitário Ministro Portela, Ininga, CEP 64049-550, Teresina - PI, Brasil.

Endereço eletrônico: denispsi@hotmail.com

Recebido em: 30/03/2012

Reformulado em: 10/06/2013

Aceito para publicação em: 15/08/2013

Acompanhamento do processo editorial: Rita Maria Manso de Barros

\section{Notas}

* Mestranda do curso de psicologia da Universidade Federal do Rio Grande do Norte - UFRN, Natal, Brasil. Especialista de Docência no Ensino Superior pela Universidade Potiguar - UnP, Natal - RN, Brasil e em Política de Assistência Social à infância e a juventude na perspectiva do Sistema Único de Assistência Social pela Universidade Potiguar - UnP, Natal - RN, Brasil.

** Doutora em Psicologia pela Universidade de São Paulo. Professor Adjunto da Universidade Federal do Rio Grande do Norte e do Programa de Pós-Graduação em Psicologia da UFRN

*** Mestrado em Desenvolvimento e Meio Ambiente, UFPI. Doutor em Psicologia pela Universidade Federal do Rio Grande do Norte. Professor Adjunto da Universidade Federal do Piauí.

${ }^{1}$ Primeiro-damismo: é a prática do assistencialismo na figura da primeira-dama. No Governo de Getúlio Vargas tivemos a presença de Darcy Vargas, que mobilizou senhoras da sociedade burguesa e outros segmentos para prestar serviços beneficentes às classes subalternas.

2 Proteção social: são as formas "às vezes mais, às vezes menos institucionalizadas que as sociedades constituem para proteger parte ou o conjunto de seus membros. Tais sistemas decorrem de certas vicissitudes da vida natural ou social, tais como a velhice, a doença, o infortúnio, as privações" (PNAS apud Di Giovanni, 2004, p. 17).

${ }^{3} \mathrm{O}$ conceito de intersetorialidade traz embutida a noção do desenvolvimento de ações integradas entre as diferentes áreas sociais - educação, saúde, habitação, assistência social e outras - e tem como princípio romper com uma visão fragmentada da política ou ação social, já que passa a exigir uma integração de objetivos, metas, procedimentos de diversos órgãos governamentais e Secretarias de Estado (Leite \& Duarte, 2005, p. 1).

4 De acordo com Libâneo (2004), a Psicologia Individualista privilegia a individualidade biológica, não assumindo os antecedentes sociais e os produtos sociais da atividade humana. Ao discutir sobre educação, o autor pontua a existência de tal perspectiva na Psicologia Humanista (Existencialismo) e na Psicanálise.

${ }^{5}$ De acordo com Lo Bianco, Bastos, Nunes e Silva (1994) são utilizados critérios para definir o tradicional e o clássico em termos de Psicologia Clínica, que são as atividades como psicodiagnóstico e/ou terapia individual ou grupal, que levam em 
Isabel Maria Farias Fernandes de Oliveira, Denis Barros de Carvalho O Psicólogo no Campo do Bem-Estar Social: atuação junto às famílias e indivíduos em situação de vulnerabilidade e risco social no CRAS

consideração o enfoque intraindividual, voltado para processos psicológicos e psicopatológicos, com uma visão de homem abstrata e a-histórica.

${ }^{6}$ Manhã de Cidadania é um vento promovido pela prefeitura de Teresina por meio da SEMTCAS, que concentra uma diversidade de atividades culturais e educativas (palestras), como inclusão e concessão de benefícios (PBF, passe livre do idoso e de pessoas com deficiência), documentação civil, ações de saúde, e acessória jurídica.

${ }^{7}$ Núcleo de Apoio Intergeracional: Instituição da Prefeitura Municipal de Teresina, de responsabilidade da SEMTCAS, que presta atendimento social, cultural e de lazer a diversas faixa etárias.

8 Transporte eficiente: beneficio da prefeitura municipal de Teresina às pessoas com deficiência.

${ }^{9}$ Os mínimos sociais visam assegurar as necessidades básicas da população que se encontra em situação de exclusão social; também estabelece parâmetros mínimos para provisão da alimentação, higiene, saúde.

${ }^{10}$ Compreende-se por papel político a busca por "estratégias de intervenção de ruptura com os mecanismos opressores presentes na sociedade atual" (Senra, 2009, p. 159). 